\title{
p63 Expression in Solid Cell Nests of the Thyroid: Further Evidence for a Stem Cell Origin
}

Jorge S. Reis-Filho, M.D., Ana Preto, M.Sc., Paula Soares, M.Sc., Ph.D., Sara Ricardo, M.T., José Cameselle-Teijeiro, M.D., Ph.D., Manuel Sobrinho-Simões, M.D., Ph.D.

Institute of Molecular Pathology and Immunology (J.S.R.-F., A.P., P.S., S.R., M.S.-S.) and Medical Faculty (P.S., M.S.-S.), University of Porto, Porto, Portugal; School of Health Sciences (J.S.R.-F.), University of Minho, Braga, Portugal; Department of Pathology (J.C.-T.), Hospital Clínico Universitario, Santiago de Compostela, Spain; and Hospital de S. João (M.S.-S.), Porto, Portugal

Solid cell nests of the thyroid are embryonic remnants of endodermal origin that may be difficult to distinguish from squamous metaplasia, metastatic squamous carcinoma, papillary microcarcinoma, medullary carcinoma, and C-cell hyperplasia. These embryonic structures are composed of main cells and C-cells; cystic structures and mixed follicles are sometimes observed intermingled with solid cell nests. Recently, p63, a p53 homologue that is consistently expressed in basal/stem cells of stratified epithelia and plays a major role in triggering the differentiation of some specific cell lineages, has been characterized. We evaluated the immunohistochemical expression of p63, cytokeratins (CAM 5.2, AE1/AE3, 34ßE12, 7, and 20), carcinoembryonic antigen, thyroid transcription factor 1 (TTF-1), thyroglobulin, and calcitonin using the streptavidinbiotin-peroxidase complex technique in 6 bona fide solid cell nests. We observed that main cells of solid cell nests are strongly decorated by $p 63$, while C-cells and all other thyroid structures were consistently negative. Moreover, main cells expressed carcinoembryonic antigen and all cytokeratins but cytokeratin 20 and lacked TTF-1, thyroglobulin and calcitonin. In contrast to this, C-cells of solid cell nests were immunoreactive for calcitonin, CAM 5.2, AE1/AE3, and cytokeratin 7; focal immunoreactivity for TTF-1 was also observed in some C-cells. We conclude that main cells of the solid cell nests display a basal/stem cell phenotype (p63 and basal cytokeratin positivity), whereas C-cells show features of parafollicular differentiation. We conclude,

Copyright (C) 2003 by The United States and Canadian Academy of Pathology, Inc.

VOL. 16, NO. 1, P. 43, 2003 Printed in the U.S.A.

Date of acceptance: October 1, 2002.

J.S.R.-F. and A.P. contributed equally to the present study.

Address reprint requests to: Prof. Manuel Sobrinho-Simões, IPATIMUP, R. Rob-

erto Frias, S/N, 4200, Porto, Portugal; e-mail: sobrinho.simoes@ipatimup.pt; fax: 351-22-557-0799.

DOI: 10.1097/01.MP.0000047306.72278.39 furthermore, that p63 antibodies may help in distinguishing solid cell nests from their mimics.

KEY WORDS: Immunohistochemistry, p63, thyroid, Ultimobranchial body.

Mod Pathol 2003;16(1):43-48

Solid cell nests of the thyroid have long fascinated pathologists since their description by Getzowa (1) in 1907. Currently, it is accepted that solid cell nests and the so-called mixed follicles are indeed ultimobranchial body remnants (2-10), but their biological significance remains disputable $(2,3,11-18)$. It has been suggested that these embryonic structures might constitute the origin of some ectopic structures rarely described in thyroid glands $(3,6)$, as well as of some peculiar types of thyroid neoplasms (17-20). Moreover, solid cell nests may be a source of confusion in thyroid pathology, as they can mimic squamous metaplasia, primary or metastatic squamous cell carcinomas, thyroglossal cyst, C-cell hyperplasia, and papillary and medullary microcarcinomas $(2,3)$.

In previous studies, our group (3) and others (2-12) have described the histological, immunohistochemical, and ultrastructural features of solid cell nests. It is accepted that solid cell nests are composed of two distinctive cell types (3): 1) main cells, which are polygonal to elongated or even spindleshaped cells with centrally located, oval to fusiform nuclei with uneven nuclear envelope showing occasional grooves, and deeply eosinophilic cytoplasm showing squamoid features (including high molecular weight cytokeratins) but lacking intercellular bridges (2-4); and 2) C-cells, which account for a minor proportion of solid cell nest population and are characterized by clear cytoplasm and centrally located, small compact nuclei (2-4). In up to $81 \%$ of the cases, mixed follicles may be found admixed with bona fide solid cell nests (2-4). Mixed follicles are composed of cells resembling main 
cells and follicular cells, forming a follicular lumenlike pattern. The lumina contain periodic acidSchiff-positive colloid-like material, acid mucins, cell debris, and periodic acid-Schiff-positive granular material $(3,5)$.

p63, a p53-homologue nuclear transcription factor, is consistently expressed in basal/stem cells of several multilayered epithelia, as well as in basal cells of the prostate acini and ducts and in basal and myoepithelial cells of the breast (21-25). p63, located on $3 q 27$, encodes six different isoforms, which harbor either transactivating (TA-p63) or negative dominant ( $\Delta N$-p63) effects on p53 reporter genes $(21-23,25)$. At variance with $\mathrm{p} 53$, which is a major tumor suppressor gene, p63 tumor suppressing properties are disputable and mutations in this gene are rather rare in human malignancies (23, 25).

It has been described that p63 acts as a nuclear transcription factor that induces the expression of cytokeratins 5 and 14, as well as other genes associated with a terminal epidermal differentiation, such as loricrin, involucrin, transglutaminase 1 , and flaggrin in basal/stem cells of several epithelial (2123). Moreover, $\Delta N$-p63 plays a major role in the maintenance of basal cell populations $(21-23,25)$. We and others also demonstrated that p63 is not expressed in follicular and parafollicular cells in normal thyroid glands $(24,26)$. According to our previous results, p63 expression in thyroid neoplasms seems to be restricted to a small subset of anaplastic carcinomas and to scattered cells in papillary carcinomas with foci of squamous differentiation $(25,26)$.

As p63 is expressed in basal/stem cells and also has been implicated in "epidermal"/squamous differentiation, we investigated the expression of p63, cytokeratins, and markers of follicular (thyroglobulin and thyroid transcription factor) and parafollicular (calcitonin and thyroid transcription factor) differentiation in six solid cell nests. We also comment on the usefulness of p63 in thyroid pathology practice.

\section{MATERIALS AND METHODS}

Six cases of thyroid diseases with solid cell nests were retrieved from the files of the Hospital Clínico Universitario, Santiago de Compostela, Spain (five cases), and from the consultation files of one of the authors (MS-S). All cases were reviewed by two of the authors (JSR-F and PS), and the clinical data were obtained either from pathology reports or from patient charts. The clinical data of the patients and underlying thyroid diseases associated with the solid cell nests are summarized in Table 1 . Formalin-fixed, paraffin-embedded tissue was available in all cases.
TABLE 1. Summary of the Patients' Clinico-Pathological Features

\begin{tabular}{cl}
\hline Age /Gender & \multicolumn{1}{c}{ Underlying Pathology } \\
\hline $39 / \mathrm{F}$ & Two follicular adenomas 3.6 and $0.8 \mathrm{~cm}$ \\
$65 / \mathrm{F}$ & Nodular/adenomatous goiter \\
$64 / \mathrm{F}$ & Nodular/adenomatous goiter \\
$55 / \mathrm{M}$ & Nodular/adenomatous goiter \\
$30 / \mathrm{M}$ & Nodular/adenomatous goiter \\
$? / \mathrm{F}$ & Papillary carcinoma \\
\hline
\end{tabular}

Immunohistochemical analysis was performed in $4 \mu \mathrm{m}$ serial sections using a panel of antibodies (Table 2) according to the streptavidin-biotinperoxidase complex technique (27). Negative (the primary antibody was substituted by nonimmune mouse serum) and positive controls were included in each slide-run. All controls gave satisfactory results. A minimum of $20 \%$ positivity was adopted as a cut-off for all markers. For p63 $(24,25)$ and thyroid transcription factor (TTF-1) (28), only nuclear immunoreactivity was considered specific, while for all of the other markers only cytoplasmic staining was accepted.

\section{RESULTS}

\section{Pathological Findings}

All cases showed solid cell nests composed of a complex admixture of main cells and C-cells as previously described (Fig. 1, A-B). In three cases, cystic structures of variable size, containing eosinophilic material and cell debris, were observed (Fig. 1A). These structures were lined by cuboidal-tocolumnar cells with eosinophilic cytoplasms and round-to-oval nuclei showing finely granular chromatin; in one case, scattered apical projections, very similar to cilia, were depicted in a minor proportion of the lining cells. Mixed follicles partially composed of main cells and partially depicting cuboidal cells with eosinophilic cytoplasm and round-to-oval nuclei was found in one case (Case 4) (Figure 1, A-B, inset).

Adjacent thyroid tissue showed typical morphological features of nodular/adenomatous goiter in four cases; in one case two follicular adenomas were observed, and in the remaining case there was a thyroid papillary carcinoma (Table 1). In the last two cases, no continuity between the thyroid neoplasms and the solid cell nests was observed.

\section{Immunohistochemical Analysis}

Table 3 summarizes the immunohistochemical findings.

p63

p63 antibody strongly decorated the nuclei of main cells in all solid cell nests (Fig. 2, A-B). Even in 


\begin{tabular}{lll}
\hline \multicolumn{1}{c}{ Antigen } & \multicolumn{1}{c}{ Antibody (Clone and Source) } & Dilution \\
\hline Thyroglobulin & Tg6, (DAKO, Glostrp, Denmark) & $1: 1000$ \\
Calcitonin & Polyclonal (BioGenex, San Ramon, CA) & $1: 200$ \\
TTF-1 & 8G7G3/1 (DAKO) & $1 / 100$ \\
Keratins 1, 5, 10, and 14 & None & $1 / 10$ \\
Keratins 1, 2, 10, 11, 14, 15, 16, and 19 & AE1/AE3 (Signet, Dedham, MA) & PC \\
Keratins 8 and 18 & CAM 5.2 (Becton Dickinson, Mountainview, CA) & $1: 5$ \\
Keratin 19 & RCK108 (DAKO) & $1: 100$ \\
Keratin 7 & OV-TL12/30 (DAKO) & $1: 50$ \\
Keratin 20 & M7019 (DAKO) & PC, P \\
Carcinoembryonic antigen & Polyclonal (DAKO) PC, P & PC, P \\
p63 & Monoclonal (Neomarkers) & PC, P \\
\hline
\end{tabular}

PC, pressure cooker; $\mathrm{P}$, protease.

low-power magnification, p63 immunoreactivity was easily observed and was restricted to solid cell nests (Fig. 2A). C-cells and the cuboidal epithelium lining the cystic structures were consistently negative for p63 (Fig. 2B). In mixed follicles, there was strong nuclear immunoreactivity in solid cell nest main cells and a gradual reduction toward the

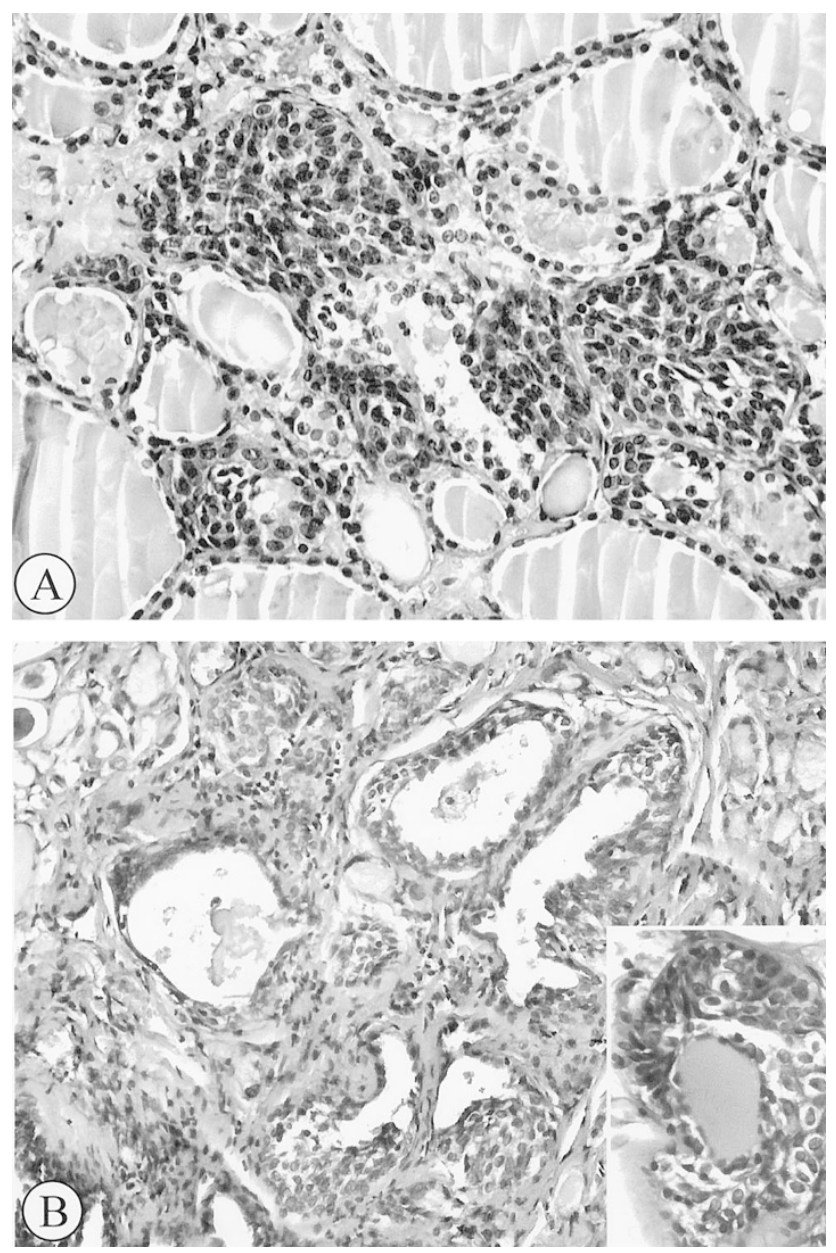

FIGURE 1. Solid cell nests-histological findings. A, Solid cell nests composed of a complex admixture of main and C-cells, as well as cystic structures. B, Cystic solid cell nest. Inset: note a mixed follicle composed of cells resembling main cells of solid cell nests and cuboidal cells arranged in a follicle-like structure (A and B, H\&E $\times 200$; Inset: $\mathrm{H} \& \mathrm{E} \times 400)$. cuboidal, follicular-like cells. In adjacent thyroid tissues, p63 immunoreactivity was not detected in any normal, hyperplastic, or parafollicular cell. Similarly, the two follicular adenomas and the papillary carcinoma were also negative for p63.

\section{Cytokeratins}

Cytokeratins AE1/AE3, CAM 5.2, and cytokeratin 19 consistently decorated both main and C-cells of all solid cell nests, as well as follicular and parafollicular cells of adjacent thyroid tissues. Cytokeratin $34 \beta \mathrm{E} 12$ was intensely expressed in main cells but was not detected in C-cells of the solid cell nests, nor in any cell of adjacent thyroid tissues (Fig. 2C). There was a concurrent expression of p63 and cytokeratin $34 \beta E 12$ in main cells of the solid cell nests. Cytokeratin 20 was not detected in solid cell nests nor in adjacent thyroid tissues.

\section{Carcinoembryonic Antigen}

Main cells and C-cells diffusely expressed carcinoembryonic antigen (Fig. 2D). No immunoreactivity in follicular cells of adjacent thyroid tissues was observed.

\section{Markers of Follicular and Parafollicular Differentiation}

In solid cell nests, the expression of TTF-1, a nuclear transcription factor that plays a major role in the development of follicular epithelium and C-cells $(28,29)$, was restricted to the nuclei of C-cells. All main cells lacked this differentiation marker (Fig. 2E). In adjacent thyroid tissues, TTF-1 was expressed in follicular and parafollicular cells, papillary carcinoma, and follicular adenomas.

Thyroglobulin is considered the most specific marker of thyroid follicular differentiation. All solid cell nests herein evaluated lacked thyroglobulin (Fig. 2F). Conversely, thyroid follicular cells and colloid, as well as all the cells of the follicular adenomas and the papillary carcinoma, were strongly positive for thyroglobulin. 
TABLE 3. Summary of the Immunohistochemical Findings

\begin{tabular}{|c|c|c|c|c|c|c|c|c|c|c|c|}
\hline Case & TG & CT & TTF-1 & $\mathrm{CK}-34 \beta \mathrm{E} 12$ & CK-AE1-AE3 & CK-CAM5.2 & CK19 & CK7 & CK20 & CEA & P63 \\
\hline 1 & - & $-*$ & $-^{*}$ & + & + & + & + & + & - & + & + \\
\hline 2 & - & $-^{*}$ & $-*$ & + & + & + & + & + & - & + & + \\
\hline 3 & - & $-*$ & $-^{*}$ & + & + & + & + & + & - & + & + \\
\hline 4 & - & $-*$ & $-*$ & + & + & + & + & + & - & + & + \\
\hline 5 & - & $-*$ & $-{ }^{*}$ & + & + & + & + & + & - & + & + \\
\hline 6 & - & - & N.D. & N.D. & N.D. & N.D. & N.D. & N.D. & N.D. & N.D. & + \\
\hline Adj FC & + & - & + & - & + & + & - & + & - & - & - \\
\hline Adj PFC & - & + & + & - & + & + & $+1-$ & - & $+1-$ & + & - \\
\hline
\end{tabular}

* Immunoreactivity restricted to C-cells; Adj FC, adjacent follicular cells; Adj PFC, adjacent parafollicular cells; CK, cytokeratin; CEA, carcinoembryonic antigen; N.D., not done.

Calcitonin staining was detected in C-cells of all solid cell nests and in parafollicular cells of adjacent thyroid tissues (Fig. 2G).

\section{DISCUSSION}

Previous immunohistochemical evaluation of solid cell nests has revealed that main cells and C-cells express high- and low-molecular weight cytokeratins $(3-8,19)$, as well as carcinoembryonic antigen, but show a differential expression of neuroendocrine markers: while main cells are usually positive for somatostatin and neurotensin, C-cells are usually immunoreactive for calcitonin and calcitonin gene-related peptide (3). Vimentin is usually negative, and thyroglobulin expression is controversial in solid cell nests $(2,8,14,19)$. In the present study, we confirmed the previously reported immunohistochemical profile of main cells and C-cells $(2-8,14,19)$.

In the present study, we observed a differential expression of p63 and TTF-1 in the nuclei of main and C-cells, respectively. p63 is consistently expressed in basal/stem cells of several types of epithelia and is usually absent in partially or terminally differentiated cells (21-25); in the present study, we demonstrated that main cells concurrently express p63 and basal cell keratin (34ßE12) and lack TTF-1 expression, thus suggesting that these cells may have a basal/stem cell status.

In contrast to main cells, C-cells lack p63 and display TTF-1, calcitonin, calcitonin gene-related peptide, and chromogranin immunoreactivity. As TTF-1 is an early marker of either follicular or parafollicular cells and the last three antigens may be interpreted as markers of terminal parafollicular (C-) cell differentiation $(27,28)$, it is tempting to speculate that C-cells of the solid cell nests have already triggered their pathways toward a parafollicular differentiation.

Mixed follicles showed a differential expression of p63, cytokeratins, TTF-1, and thyroglobulin: while cells resembling main cells were strongly positive for p63 and cytokeratins $34 \beta \mathrm{E} 12$ and lacked TTF- 1 and thyroglobulin, cuboidal cells arranged in follicular-like pattern were positive for thyroglobu- lin and TTF-1 and were negative for p63 and cytokeratins $34 \beta \mathrm{E} 12$. These findings suggest that those cells arranged in follicular-like structures have also triggered their differential pathways toward a follicular differentiation.

Our hypothesis that solid cell nests display a basal/stem cell phenotype is supported, indirectly, by the presence of adipose, cartilage, and salivary gland-type tissues in the vicinity of or even abutting solid cell nests-what has been advanced as evidence to support the concept that solid cell nests represent a dysembryological process $(3,14,16)$.

Solid cell nests may pose some difficulties in routine thyroid pathology practice. Harach (2) and Cameselle-Teijeiro et al. (3) stressed that solid cell nests may be confused with squamous metaplasia, metastatic squamous carcinoma, papillary microcarcinoma, medullary carcinoma, and C-cell hyperplasia $(2,3)$. It has been assumed that using judicious morphological evaluation and based on the so-called typical immunohistochemical profile of solid cell nests (carcinoembryonic antigen and "epidermal" keratins), they might be differentiated from their mimics $(2,3)$. However, it should be noted that some neuroendocrine carcinomas and primary or metastatic mucoepidermoid carcinomas may co-express carcinoembryonic antigen and "epidermal"/high molecular weight cytokeratins (18, 20, 30-32). p63 immunoreactivity may help in the identification of solid cell nests. p63 is not expressed by follicular and parafollicular $(\mathrm{C}-)$ cells $(24,26)$, is absent in medullary and follicular carcinomas $(24,25)$. In a previous study $(26)$, we evaluated the expression of p63 in 12 papillary carcinomas of the thyroid and found out that 4 cases focally expressed p63 in 5-30\% of the cells (26). Interestingly, p63 expression was almost restricted to foci of squamous differentiation (26). Altogether, it seems that p63 may be a useful marker to distinguish solid cell nests from papillary and medullary carcinomas, as well as from C-cell hyperplasia. However, p63 seems to play a very limited role, or no role, as an adjunct antibody in the differentiation between solid cell nests and foci of squamous metaplasia. 

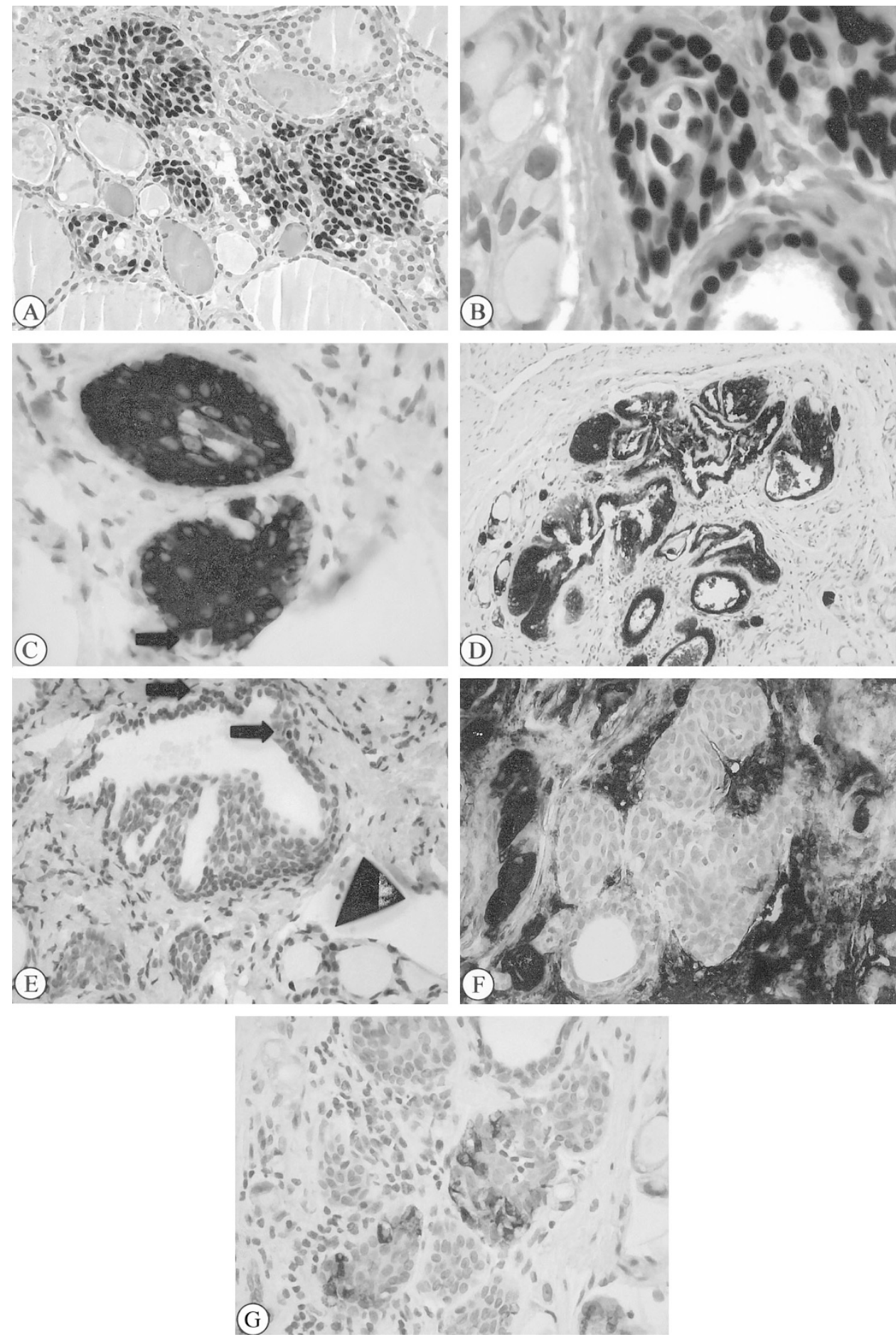

FIGURE 2. A, p63 expression in the nuclei of main cells and rare C-cells. Note that all cystic structures and mixed follicles consistently lack p63 expression. B, High power magnification of a solid cell nest showing strong nuclear immunoreactivity for p63 in main cells and lack of p63 in a solid cell nest (arrowhead). C, Cytokeratin 34ßE12 expression in solid cell nests. Note that some c-cells lack p63 expression (arrow). D, Solid cell nest stained with carcinoembryonic antigen. At the periphery, note immunoreactivity in scattered parafollicular (C-) cells. E, TTF-1 expression in a cystic solid cell nest. Note rare cells expressing TTF-1 (arrows). On lower right, TTF-1 decorated all follicular cells of normal thyroid follicles. F, Follicular cells and thyroid stroma stained with thyroglobulin. Solid cell nests were negative for this marker. G, Calcitonin immunoreactivity in scattered C-cells of solid cell nests (Streptavidin-biotin-peroxidase; A, E, F, and G, original magnification 200×; B, C, 400×; D, 100×).

In conclusion, our results demonstrate that main cells of the solid cell nests concurrently express p63 (a basal/stem cell marker) and basal cytokeratins, while C-cells lack p63 and show parafollicular differentiation markers (TTF-1, calcitonin, carcinoem- bryonic antigen). Based on these findings, we suggest that main cells of the solid cell nests display a basal/stem cell phenotype. Moreover, we advocate that antibodies against p63 should be included in immunohistochemical panels to distinguish solid 
cell nests from their mimics, namely from medullary and papillary microcarcinomas.

Acknowledgments: This study was partially supported by Ph.D. Grants from the Portuguese Science and Technology Foundation (FCT) (references PRAXIS XXI/BD/21795/99 - AP and SFRH/BD/5386/ 2001 - JSRF) and Programa Operacional Ciência, Tecnologia e Inovação (POCTI) do Quadro Comunitário de Apoio (QCA) II.

\section{REFERENCES}

1. Getzowa S. Ueber die Glandula parathyreoidea, intrathyreoidale Zellhaufen derselben und Reste des postbranchialen köpers. Virchows Arch A Pathol Anat Histopathol 1907;188: 181-234.

2. Harach HR. Solid cell nests of the thyroid. J Pathol 1988;155: 191-200.

3. Cameselle-Teijeiro J, Varela-Duran J, Sambade C, Villanueva JP, Varela-Nunez R, Sobrinho-Simoes M. Solid cell nests of the thyroid: light microscopy and immunohistochemical profile. Hum Pathol 1994;25:684-93.

4. Martin V, Martin L, Viennet G, Hergel M, Carbillet JP, Fellmann D. Ultrastructural features of "solid cell nest" of the human thyroid gland: a study of 8 cases. Ultrastruct Pathol 2000;24:1-8.

5. Harach HR. Mixed follicles of the human thyroid gland. Acta Anat (Basel) 1987;129:27-30.

6. Bykov VL. Tissue of ultimobranchial origin in normal and pathologically altered thyroid gland. Arkh Patol 1993;55:81-4.

7. Fraser BA, Duckworth JW. Ultimobranchial body cysts in the human foetal thyroid: pathological implications. J Pathol 1979;127:89-92.

8. Mizukami Y, Nonomura A, Michigishi T, Noguchi M, Hashimoto T, Nakamura S, et al. Solid cell nests of the thyroid. A histologic and immunohistochemical study. Am J Clin Pathol 1994;101:186-91.

9. Ozaki O, Ito K, Sugino K, Yasuda K, Yamashita T, Toshima K, et al. Solid cell nests of the thyroid gland. Virchows Arch A Pathol Anat Histopathol 1991;418:201-5.

10. Beckner ME, Shultz JJ, Richardson T. Solid and cystic ultimobranchial body remnants in the thyroid. Arch Pathol Lab Med 1990;114:1049-52.

11. Martin V, Martin L, Viennet G, Challier B, Carbillet J, Fellmann D. Solid cell nests and thyroid pathologies. Retrospective study of 1,390 thyroids. Annu Pathol 2000;20:196-201.

12. Williams ED, Toyn CE, Harach HR. The ultimobranchial gland and congenital thyroid abnormalities in man. J Pathol 1989;159:135-41.

13. Chan JK, Tse CC. Solid cell nest-associated C-cells: another possible explanation for "C-cell hyperplasia" adjacent to follicular cell tumors. Hum Pathol 1989;20:498-9.

14. Janzer RC, Weber E, Hedinger C. The relation between solid cell nests and $\mathrm{C}$ cells of the thyroid gland: an immunohistochemical and morphometric investigation. Cell Tissue Res 1979;197:295-312.

15. Fraser BA, Duckworth JW. Position of ultimobranchial body cysts in the human fetal thyroid gland. Acta Anat (Basel) 1979;105:269-72.
16. Cameselle-Teijeiro J, Varela-Duran J. Intrathyroid salivary gland-type tissue in multinodular goiter. Virchows Arch 1994;425:331-4.

17. Cameselle-Teijeiro J. Mucoepidermoid carcinoma and solid cell nests of the thyroid. Hum Pathol 1996;27:861-3.

18. Cameselle-Teijeiro J, Febles-Perez C, Sobrinho-Simoes M. Papillary and mucoepidermoid carcinoma of the thyroid with anaplastic transformation: a case report with histologic and immunohistochemical findings that support a provocative histogenetic hypothesis. Pathol Res Pract 1995;191:1214-21.

19. Harach HR, Vujanic GM, Jasani B. Ultimobranchial body nests in human fetal thyroid: an autopsy, histological, and immunohistochemical study in relation to solid cell nests and mucoepidermoid carcinoma of the thyroid. J Pathol 1993;169:465-9.

20. Harach HR. A study on the relationship between solid cell nests and mucoepidermoid carcinoma of the thyroid. Histopathology 1985;9:195-207.

21. Mills AA, Zheng B, Wang XJ, Vogel H, Roop DR, Bradley A. p63 is a p53 homologue required for limb and epidermal morphogenesis. Nature 1999;398:708-13.

22. Yang A, Schweitzer R, Sun D, Kaghad M, Walker N, Bronson RT, et al. p63 is essential for regenerative proliferation in limb, craniofacial and epithelial development. Nature 1999; 398:714-8.

23. Levrero M, De Laurenzi V, Costanzo A, Gong J, Wang JY, Melino G. The p53/p63/p73 family of transcription factors: overlapping and distinct functions. J Cell Sci 2000;113:166170.

24. Di Como CJ, Urist MJ, Babayan I, Drobnjak M, Hedvat CV, Teruya-Feldstein J, et al. p63 Expression Profiles in Human Normal and Tumor Tissues. Clin Cancer Res 2002;8:494-501.

25. Reis-Filho JS, Schmitt FC. Taking advantage of basic research: p63 is a reliable myoepithelial and stem cell marker. Adv Anat Pathol 2002;9:280-9.

26. Preto A, Reis-Filho JS, Ricardo S, Soares P. p63 expression in papillary and anaplastic carcinomas of the thyroid gland: lack of an oncogenetic role in tumorigenesis and progression. Pathol Res Pract 2002;198:449-54.

27. Reis-Filho JS, Milanezi F, Silva P, Schmitt FC. Maspin expression in myoepithelial tumors of the breast. Pathol Res Pract 2001;197:817-21.

28. Reis-Filho JS, Carrilho C, Valenti C, Leitao D, Ribeiro CA, Ribeiro SG, et al. Is TTF1 a good immunohistochemical marker to distinguish primary from metastatic lung adenocarcinomas? Pathol Res Pract 2000;196:835-40.

29. Ordonez NG. Thyroid transcription factor-1 is a marker of lung and thyroid carcinomas. Adv Anat Pathol 2000;7:123-7.

30. Sturm N, Lantuejoul S, Laverriere MH, Papotti M, Brichon PY, Brambilla C, et al. Thyroid transcription factor 1 and cytokeratins 1, 5, 10, 14 (34betaE12) expression in basaloid and large-cell neuroendocrine carcinomas of the lung. Hum Pathol 2001;32:918-25.

31. Schroder S, Wodzynski A, Padberg B. Cytokeratin expression of benign and malignant epithelial thyroid gland tumors. An immunohistologic study of 154 neoplasms using 8 different monoclonal cytokeratin antibodies. Pathologe 1996;17:42532.

32. Baloch ZW, Solomon AC, LiVolsi VA. Primary mucoepidermoid carcinoma and sclerosing mucoepidermoid carcinoma with eosinophilia of the thyroid gland: a report of nine cases. Mod Pathol 2000;13:802-7. 